\title{
Produção da alface em função do uso de diferentes fontes de fósforo em solo de Cerrado
}

\author{
Regina Maria Q. Lana; Luiz Antônio Zanão Júnior; José Magno Q. Luz; Julierme Cândido da Silva \\ ${ }^{1}$ Universidade Federal de Uberlândia, ICIAG, C. Postal 593, 38400-902 Uberlândia-MG; E-mail: rmqlana@iciag.ufu.br
}

\begin{abstract}
RESUMO
A alface (Lactuca sativa L.) é uma hortaliça bastante exigente em fósforo, sendo pouco tolerante à acidez do solo. O objetivo deste trabalho foi avaliar a resposta da cultura da alface a diferentes fontes de fertilizantes fosfatados solúveis e reativos de lenta solubilidade, na presença de calagem, visando aumento da produtividade. Utilizou-se o delineamento em blocos casualizados, com seis tratamentos (superfosfato simples, termofosfato magnesiano, superfosfato triplo, Fosmag, fosfato reativo de Arad e testemunha na ausência de fósforo), em quatro repetições, conduzido em um latossolo vermelho Distrófico. Na ausência de fósforo obtiveram-se menores produções e diâmetro de plantas, bem como todas as demais variáveis de crescimento, indicando elevada resposta de fósforo pela cultura da alface. Houve resposta significativa às diferentes fontes de fósforo, no que diz respeito à massa fresca e seca da parte aérea, massa fresca de raízes e teor de $\mathrm{P}$ no solo, em ordem decrescente com as fontes Fosmag, superfosfato triplo, superfosfato simples, termofosfato magnesiano e fosfato reativo de Arad. Com relação à massa seca de raízes e diâmetro das plantas, as fontes Fosmag e superfosfato triplo foram equivalentes. Os teores de $\mathrm{P}$ acumulados nas folhas foram superiores para as fontes Fosmag, superfosfato triplo e superfosfato simples, quando comparados com o termofosfato magnesiano e Arad, em condições em que a acidez foi corrigida.
\end{abstract}

\begin{abstract}
Lettuce yield under different phosphorus sources use in the cerrado soil

The lettuce (Lactuca sativa L.) is a very demanding crop for phosphorus, being little tolerant to the soil acidity. The response of the lettuce crop to sources of soluble and reactive phosphorus fertilizer of slow solubility was evaluated in the presence of liming. . The experimental design consisted of a randomizing complete block design with six treatments (single superphosphate, thermalphosphate magnesium, triple superphosphate, Fosmag, Arad phosphate rock and control without phosphorus), in four replications, conducted in a Typic Acrustox. P suppression, yield and plant diameter indicate, as well as all other variables related to plant growth, the importance of $\mathrm{P}$ for the lettuce development. Significant responses to different $\mathrm{P}$ sources were also observed for fresh and dry matter production of aerial part, fresh mass of roots and level of $\mathrm{P}$ in the soil. Best responses in decreasing order were obtained for Fosmag, triple superphosphate, single superphosphate, thermalphosphate magnesium and Arad phosphate rock match sources. Fosmag and triple superphosphate were equivalent for production of root dry mass and diameter of the aerial part. Adjusting soil acidity, the accumulated level of $P$ in leaves was higher when Fosmag, triple superphosphate and simple superphosphate were used as sources of P.
\end{abstract}

Keywords: Lactuca sativa L., liming, fertilization, phosphate.

Palavras-chave: Lactuca sativa L., calagem, adubação, fosfatos.

(Recebido para publicação em 30 de outubro de 2003 e aceito em 14 de abril de 2004)

$\mathrm{O}_{\mathrm{s}}^{\mathrm{s}}$ solos sob vegetação de cerrado, principalmente os latossolos, apresentam limitações de ordem química para o adequado crescimento das plantas, com destaque para os baixos teores de nutrientes e a elevada capacidade de adsorção de fosfato. A baixa eficiência das adubações fosfatadas evidencia a necessidade de novos métodos de adubação no que diz respeito a fontes, épocas de aplicação e localização do adubo (Guimarães et al., 1993). Em solos ácidos e com baixos teores de fósforo, este nutriente limita a produtividade das culturas.

A fixação do fósforo, muitas vezes, pode ser diminuída pelo aumento do $\mathrm{pH}$ do solo. Resultados de vários experimentos mostram que se o $\mathrm{pH}$ for mantido entre 6,0 e 7,0, ocorre melhor absorção de P pelas culturas (Malavolta,
1989; Novais e Smyth, 1999; Van Raij, 1991).

Em solos com pH alto, o fósforo é insolubilizado como fosfato de cálcio, e naqueles com pH baixo é fixado, como fosfatos de alumínio e de ferro. As reações do fósforo no solo podem envolver tanto adsorção quanto precipitação (Lin et al., 1983; Jayachandran et al., 1989). Muitos pesquisadores acreditam que o mecanismo de adsorção ocorre quando existe baixa concentração de fósforo, e a precipitação, quando altas concentrações deste nutriente estão presentes no solo (Lin et al., 1983). Fabres et al. (1987), estudando os níveis críticos de diferentes frações de fósforo em plantas de alface cultivadas em diferentes solos, verificaram que as características dos solos associadas à adsorção de $\mathrm{P}$ exercem significativa influência so- bre a distribuição dessas frações na parte aérea, e que as concentrações críticas de $\mathrm{P}$ total e $\mathrm{P}$ inorgânico variaram inversamente com a capacidade tampão de $\mathrm{P}$ dos solos, enquanto a concentração crítica do P orgânico, aparentemente, não foi influenciada.

A alface pode ser considerada como bastante exigente em fósforo, principalmente na fase final de seu ciclo. A deficiência deste elemento reduz em muito o crescimento da planta, havendo má formação da cabeça, coloração verdeopaca das folhas velhas, podendo mostrar tonalidades vermelho-bronze ou púrpura (Katayama, 1993). Poucos trabalhos são encontrados descrevendo o uso de fontes fosfatadas na cultura da alface e, até mesmo, em outras hortaliças folhosas cultivadas em solos de cerrado. Nakagawa et al. (1989) estudaram 
o efeito de cinco adubos fosfatados (termofosfato magnesiano Yoorin e Yookarim, fosfato parcialmente acidulado, superfosfato simples e hiperfosfato), na ausência e na presença de calagem, na produção do rabanete e rúcula. Verificaram que na presença de calagem os termofosfatos magnesianos foram as melhores fontes, tendo o hiperfosfato apresentado resultados inferiores.

Os adubos fosfatados mais utilizados na agricultura brasileira são os fosfatos solúveis, termofosfatos, multifosfatos e fosfatos naturais e ainda os fertilizantes fosfatados parcialmente acidulados. Segundo Malavolta (1980) produtos de origem orgânica têm sido complementos de grande valor. Por este motivo, a escolha de uma fonte de $\mathrm{P}$ normalmente se baseia tanto na sua eficiência em suprir $\mathrm{P}$ para as plantas como na sua relação custo:benefício (Goedert et al., 1985).

Comumente tem sido recomendado o superfosfato triplo e superfosfato simples como fontes de fósforo. Atualmente, outras fontes reativas de menor solubilidade têm apresentado bons resultados na produtividade de diversas culturas. Este trabalho avaliou o uso de diferentes fontes de fertilizantes fosfatados solúveis e reativos de menor solubilidade, em solo com $\mathrm{pH}$ corrigido, sobre a produtividade da alface (Lactuca sativa L.).

\section{MATERIAL E MÉTODOS}

O experimento foi conduzido em campo, na Universidade Federal de Uberlândia (MG), em dezembro de 1999. O solo utilizado foi um latossolo vermelho Distrófico típico, de textura muito argilosa, elevada acidez, baixa saturação por bases, baixos teores de fósforo, magnésio e cálcio e alta saturação por alumínio.

As mudas foram produzidas em casa-de-vegetação, utilizando-se sementes peletizadas da cultivar Verônica, que foram semeadas em bandejas de isopor de 200 células, contendo substrato comercial Plantmax ${ }^{\circledR}$. A irrigação das mudas foi feita duas vezes ao dia, na proporção de $500 \mathrm{ml}$ por vez, por bandeja.

O solo foi arado a $20 \mathrm{~cm}$ de profundidade, e logo após foram demarcados os canteiros de 1,2 $\mathrm{m}$ de largura e parcelas com 1,2 m de comprimento. As mudas foram transplantadas para os canteiros 26 dias após a semeadura, no espaçamento de $20 \times 20 \mathrm{~cm}$, totalizando 16 plantas por parcela, sendo a parcela útil composta apenas das quatro plantas centrais. O delineamento foi em blocos ao acaso com seis tratamentos em quatro repetições. Os tratamentos constituíram-se de cinco fontes de fósforo (multifosfato magnesiano - Fosmag, superfosfato simples, superfosfato triplo, termofosfato magnesiano, fosfato reativo de Arad) e ausência de fósforo. Para as fontes fosfatadas foi realizada a determinação da solubilidade em água, citrato neutro de amônio (C.N.A.), $\mathrm{HCl}$ $1+1$ (fósforo total) e em ácido cítrico $2 \%$ segundo Horwitz (1970) e adotados os parâmetros descritos pela Legislação Brasileira sobre Inspeção e Fiscalização do Comércio de Fertilizantes, Corretivos e Inoculantes (Brasil,1983).

Fez-se a calagem visando elevar a saturação por bases para $70 \%$, conforme o recomendado pelo boletim de Recomendações para o uso de corretivos e fertilizantes em Minas Gerais, segundo Ribeiro et al. (1999), aplicando-se 2,5 $\mathrm{t} \mathrm{ha}^{-1}$ de calcário dolomítico calcinado (PRNT 100\%). Utilizou-se uma dose de fósforo equivalente a $300 \mathrm{~kg} \mathrm{ha}^{-1} \mathrm{de}_{2} \mathrm{O}_{5}$, calculadas com base no teor solúvel em ácido cítrico. As doses foram estabelecidas segundo Ribeiro et al. (1999). As fontes foram aplicadas dez dias antes do transplantio das mudas, sendo a aplicação realizada a lanço visando elevar o teor de fósforo na área total.

As adubações nitrogenada e potássica foram feitas parcialmente no sulco de plantio e posteriormente, em cobertura aos 17, 31 e 38 dias após o transplantio, totalizando doses correspondentes a $150 \mathrm{~kg} \mathrm{ha}^{-1} \mathrm{de} \mathrm{N}$ (sulfato de amônio) e $90 \mathrm{~kg} \mathrm{ha}^{-1}$ de $\mathrm{K}_{2} \mathrm{O}$ (cloreto de potássio), estabelecidas de acordo com Ribeiro et al. (1999).

Aos 46 dias após o transplantio, a alface foi colhida para determinação do diâmetro das plantas, produções de matéria fresca e seca da parte aérea e das raízes e os teores de fósforo foliar e no solo. As plantas foram retiradas com o solo aderido às suas raízes, por meio de enxada, de modo a não danificá-las e evitar perda da parte do sistema radicular. Posteriormente, o caule foi separado da parte aérea. As raízes foram lavadas cuidadosamente até a retirada do solo aderido às mesmas. $\mathrm{O}$ excesso de água das raízes foi retirado com o auxílio de papel toalha e em seguida o material foi pesado.

A determinação da matéria seca da parte aérea e das raízes foi feita por meio da secagem dos materiais coletados em estufa de circulação forçada de ar a $70^{\circ} \mathrm{C}$ até peso constante com posterior pesagem.

$\mathrm{Na}$ análise das folhas para determinação dos teores de $\mathrm{P}$ utilizou-se a metodologia recomendada por Bataglia et al. (1985). Fez-se amostragem de solo em cada parcela, na profundidade de 0 $20 \mathrm{~cm}$, retirando três amostras simples para formação de uma composta para determinação do teor de P-lábil do solo, de acordo com metodologia descrita pela Embrapa (1997).

A eficiência relativa das fontes de fósforo foi determinada por meio da equação IEA $=\left(\mathrm{Y}_{2}-\mathrm{Y}_{0} / \mathrm{Y}_{1}-\mathrm{Y}_{0}\right) \times 100$, em que $Y_{0}$ refere-se à produção obtida pela parcela, sem o nutriente; $\mathrm{Y}_{1}$, refere-se à produção com uma dose determinada do nutriente, usando o adubo padrão, que neste caso é o superfosfato triplo; e $\mathrm{Y}_{2}$ é a produção com a mesma dose do nutriente, usando o adubo a ser avaliado (Van Raij, 1991). Os dados foram submetidos à analise de variância e ao teste de médias de Tukey, a 5\% de probabilidade.

\section{RESULTADOS E DISCUSSÃO}

As produções de matérias fresca e seca da parte aérea e raízes, o diâmetro de plantas e os teores de fósforo foliar e no solo apresentaram diferenças significativas quanto às fontes de fósforo (Tabelas 1 e 2).

$\mathrm{O}$ uso de Fosmag resultou em maior peso tanto de matéria seca como de matéria fresca da parte aérea da alface, bem como, a obtenção de maior peso de matéria fresca das raízes. Além disso, observou-se neste tratamento a presença de teores mais elevados de fósforo no solo (Tabelas 1 e 2). O maior teor de fósforo disponível no solo pelo Fosmag provavelmente se deve tanto ao 
alto teor de $\mathrm{P}$ solúvel em ácido cítrico (18\%), quanto à menor adsorção do $\mathrm{P}$ ao solo.

$\mathrm{Na}$ ausência de fósforo, observouse significativa redução no peso da matéria fresca da parte aérea e seca de raízes, marcante diminuição do diâmetro de plantas e elevada redução dos teores de fósforo acumulado nas folhas, evidenciando a elevada exigência da alface em fósforo (Tabelas 1 e 2).

Avaliou-se a eficiência das fontes de fósforo em relação ao superfosfato triplo, considerado padrão (100\%) e obteve-se para o Fosmag uma eficiência de $138 \%, 135 \%$ e $117 \%$, respectivamente para produção de matéria fresca, matéria seca e diâmetro de plantas (Figura 1). $\mathrm{O}$ superfosfato simples, em relação à produção de matéria fresca, teve uma eficiência de $91 \%$ em relação ao superfosfato triplo e $95 \%$ sobre o diâmetro de plantas (Figura 1). O termofosfato magnesiano teve uma eficiência entre 70 a $80 \%$ sobre as variáveis de crescimento. A fonte fosfato de Arad, nas condições deste trabalho, apresentou baixa eficiência, obtendo índices de $26 \%, 23 \%, 40 \%$ e $16 \%$, respectivamente para matérias fresca e seca de folhas, diâmetro de plantas e teor de fósforo foliar em relação ao superfosfato triplo. Quanto à presença de fósforo na folha, as fontes Fosmag e superfosfato triplo apresentaram teores equivalentes deste elemento obtendo-se, portanto, a mesma eficiência relativa quanto ao teor de P foliar (Figura 1).

Kaminski e Peruzzo (1997), indicaram que os mais altos rendimentos de grãos de milho foram alcançados nos tratamentos adubados com fosfato solúvel aplicado no plantio. Já no segundo e terceiro cultivos, os fosfatos se equivaleram no fornecimento de fósforo para as plantas. Isto indica que os fosfatos solúveis são fontes mais adequadas de fósforo. Mas, em períodos mais longos, há um efeito compensatório do fosfato natural reativo, como destacado por Rein et al. (1994).

Os efeitos positivos do Fosmag sobre a produtividade da alface provavelmente, devem-se ao fato de o fósforo neste composto estar sob uma forma disponível, solúvel em citrato neutro de amônio mais água, porém com libera-

Tabela 1. Peso médio de matérias fresca e seca da parte aérea (MFPA e MSPA) e das raízes (MFR e MSR) e diâmetro de plantas de alface (DPA), em função do uso de diferentes fontes de fósforo. Uberlândia, UFU, 1999.

\begin{tabular}{|c|c|c|c|c|c|}
\hline Tratamentos & $\begin{array}{c}\text { MFPA } \\
\left(\text { g }_{\text {planta }}{ }^{-1}\right)\end{array}$ & $\begin{array}{c}\text { MSPA } \\
\left({\left.\text { g } \text { planta }^{-1}\right)}^{2}\right.\end{array}$ & $\begin{array}{c}\text { MFR } \\
\left(\text { g }_{\text {planta }}{ }^{-1}\right)\end{array}$ & $\begin{array}{c}\text { MSR } \\
\left(\text { g planta }^{-1}\right)\end{array}$ & DPA $(\mathrm{cm})$ \\
\hline$\overline{F G}$ & 123,75 a & $19,68 \mathrm{a}$ & $14,37 \mathrm{a}$ & $1,56 \mathrm{a}$ & 22,68 a \\
\hline ST & $100,31 b$ & $16,87 \mathrm{~b}$ & $12,81 \mathrm{~b}$ & $1,56 \mathrm{a}$ & $21,37 a b$ \\
\hline SS & $94,68 \mathrm{c}$ & $15,00 \mathrm{~b}$ & $11,87 \mathrm{bc}$ & $1,25 b$ & $20,93 \mathrm{~b}$ \\
\hline TM & $85,62 \mathrm{~d}$ & $14,68 \mathrm{~b}$ & $10,93 \mathrm{c}$ & $1,12 \mathrm{c}$ & $19,87 \mathrm{bc}$ \\
\hline AR & $54,06 \mathrm{e}$ & $10,62 \mathrm{c}$ & $10,62 \mathrm{c}$ & $1,12 \mathrm{c}$ & $16,81 \mathrm{c}$ \\
\hline TE & $38,12 \mathrm{f}$ & $8,75 \mathrm{c}$ & $9,12 \mathrm{~d}$ & $0,93 d$ & $13,68 d$ \\
\hline 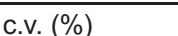 & 13 & 9 & 11 & 14 & 16 \\
\hline
\end{tabular}

Médias seguidas por letras distintas na mesma coluna, diferem entre si a 5\% de probabilidade pelo teste de Tukey. Termofosfato magnesiano (TM), superfosfato triplo (ST), superfosfato simples (SS), Fosmag (FG), fosfato reativo de Arad (AR), testemunha (sem aplicação de fósforo, TE).

Tabela 2. Valores médios dos teores de fósforo foliar (P foliar) e fósforo no solo (P solo), em função do uso de diferentes fontes de fósforo. Uberlândia, UFU, 1999.

\begin{tabular}{|c|c|c|}
\hline Tratamentos & $P$ foliar $\left(\mathrm{g} \mathrm{kg}^{-1}\right)$ & P solo $\left(\mathrm{mg} \mathrm{dm}^{-3}\right)$ \\
\hline$\overline{F G}$ & $1,9 a$ & 49,8 a \\
\hline ST & $1,9 a$ & $41,9 \mathrm{~b}$ \\
\hline SS & $1,8 \mathrm{a}$ & $33,3 \mathrm{c}$ \\
\hline TM & $1,6 \mathrm{~b}$ & $27,2 \mathrm{~d}$ \\
\hline AR & $1,2 \mathrm{c}$ & $27,0 \mathrm{~d}$ \\
\hline TE & $1,1 \mathrm{~d}$ & $3,7 \mathrm{e}$ \\
\hline c.v. (\%) & 19 & 17 \\
\hline
\end{tabular}

Médias seguidas por letras distintas na mesma coluna, diferem entre si a 5\% de probabilidade pelo teste de Tukey. Termofosfato magnesiano (TM), superfosfato triplo (ST), superfosfato simples (SS), Fosmag (FG), fosfato reativo de Arad (AR), testemunha (sem aplicação de fósforo, TE). "D.M.S. = 0,08 ;

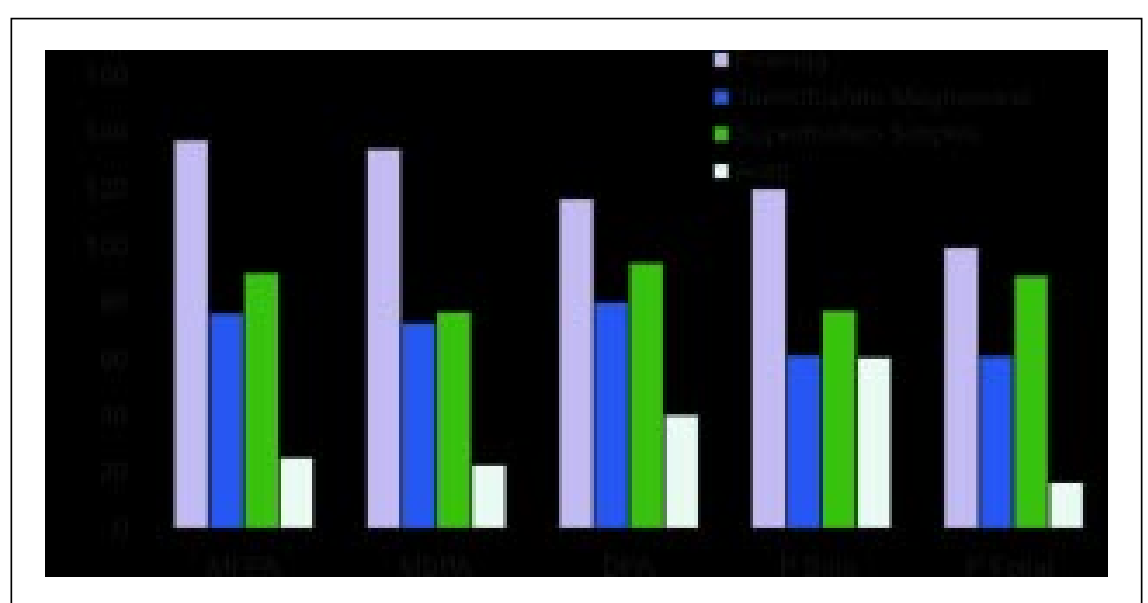

Figura 1. Eficiência relativa das fontes de fósforo em relação ao superfosfato triplo (100\%), considerando a produção de matérias fresca e seca da parte aérea (MFPA e MSPA), diâmetro de plantas de alface (DPA) e teores de fósforo foliar (P foliar) e no solo (P solo). Uberlândia, UFU, 1999.

ção gradual, dando características específicas ao fertilizante, diminuindo a fixação do fósforo. O fósforo encontrase ligado ao magnésio no mesmo grâ- nulo, favorecendo sua absorção pelas plantas, devido ao efeito sinérgico da interação fósforo $\mathrm{X}$ magnésio. $\mathrm{O}$ Fosmag apresenta solubilidade equili- 
brada em solos com $\mathrm{pH}$ corrigido na faixa de 5,5 a 6,5.

O fosfato reativo de Arad apresentou baixa disponibilidade de fósforo na solução, o que refletiu num baixo teor de $\mathrm{P}$ na folha e, conseqüentemente, baixas produtividades e diâmetro das plantas (Tabela 1), provavelmente devido ao solo estar com acidez corrigida, o que reduziu a solubilização do fósforo nesta fonte.

$\mathrm{O}$ maior teor de $\mathrm{P}_{2} \mathrm{O}_{5}$ total entre os fosfatos naturais não é indício de menor grau de substituições isomórficas, ou mesmo de menor solubilidade, mas resultado do processo de concentração ao qual foi submetido. Os fosfatos possuem diferentes teores de $\mathrm{P}_{2} \mathrm{O}_{5}$ total e solúvel em ácido cítrico.

Nas culturas de aveia, soja e trigo, cultivadas em solos com acidez corrigida tem-se observado maior eficiência do superfosfato triplo quando comparado ao fosfato Arad como fontes de fósforo (Rein et al., 1994). A maior eficiência do superfosfato triplo refletiu-se na maior produção de massa seca de aveia e na maior produção de grãos de soja e trigo. De acordo com estes autores, isto ocorreu pois o superfosfato usado nas mesmas doses do Arad proporcionou incrementos maiores no fósforo lábil do solo do que o fosfato natural, elevando a classe de disponibilidade em nível médio ou próximo do suficiente. Tais resultados confirmam não só a eficiência do fosfato solúvel como fonte de fósforo, mas também, sua maior eficácia na construção de fertilidade de solos com baixo teor inicial deste nutriente.

As fontes de fósforo reagem diferentemente em função das características do solo, como: acidez, teor de alumínio trocável, nível de fósforo no solo, capacidade de adsorção de fósforo, poder tampão do solo; bem como características da planta (sistema radicular, CTC das raízes, exsudação de compostos ácidos ou básicos, dentre outros) (Fageria et al., 1999).

Os teores de fósforo no solo após o cultivo, extraídos com Mehlich-1, foram superiores nos tratamentos com Fosmag e superfosfato triplo, indicando maior solubilização destas fontes em solo com $\mathrm{pH}$ corrigido para valores próximos de
6,5 (Tabela 2). O valor de P no solo obtido com o fosfato reativo Arad, provavelmente está superestimado na análise pelo uso do extrator Mehlich-1, que é um ácido duplo, solubilizando o fosfato além do que o disponível para a planta. Isto justifica a baixa produção de massa fresca da alface na presença do fosfato Arad, mesmo estando o teor de P no solo elevado.

$\mathrm{Na}$ ausência de fósforo obtiveramse menores produções e diâmetro de plantas, bem como valores mais baixos em todas as variáveis relacionadas ao bom desenvolvimento da planta indicando que a alface responde positivamente a teores mais elevados deste nutriente no solo.

A cultura da alface respondeu significativamente às diferentes fontes de fósforo, no que diz respeito à massa fresca e seca da parte aérea, massa fresca de raízes e teor de $\mathrm{P}$ no solo, em ordem decrescente com as fontes Fosmag, superfosfato triplo, superfosfato simples, termofosfato magnesiano e fosfato reativo de Arad.

Com relação a massa seca de raízes e diâmetro das plantas, as fontes Fosmag e superfosfato triplo foram equivalentes.

Os teores de $\mathrm{P}$ acumulados nas folhas foram superiores e equivalentes para as fontes Fosmag, superfosfato triplo e superfosfato simples, quando comparados com o termofosfato magnesiano e Arad, em condições de acidez corrigida.

\section{LITERATURA CITADA}

BATAGLIA, O.C.; FURLANI, A.M.C.; TEIXEIRA, J.P.F.; FURLANI, P.R.; GALLO, J.R. Métodos de análise química de plantas. Campinas: Instituto Agronômico, 1985. 48 p. (Boletim Técnico, 78).

BRASIL. Secretaria Nacional de Defesa Agropecuária. Inspeção e Fiscalização da produção e do comércio de fertilizantes, corretivos, inoculantes, estimulantes ou biofertilizantes destinados à agricultura: Legislação. s.1.: Divisão de Fiscalização de corretivos e fertilizantes, 1983. 88 p.

EMPRESA BRASILEIRA DE PESQUISA AGROPECUÁRIA. Centro Nacional de Pesquisa de Solos (Rio de Janeiro, RJ). Manual de métodos de análises de solo. 2. ed. Rio de Janeiro: Embrapa-CNPS, 1997. 212 p.

FABRES, A.S.; NOVAIS, R.F.; NEVES, J.C.L.; BARROS, N.F.; CORDEIRO, A.T. Níveis críticos de diferentes frações de fósforo em plantas de alface cultivadas em diferentes solos. Revista Brasileira de Ciência do Solo, Viçosa, v.11, n.1, p.5157. 1987.
FAGERIA, N.K.; STONE, L.F.; SANTOS, A.B. Manejo de nutrientes para produção eficiente das culturas. In: Maximização da Eficiência de produção das culturas. Brasília: Embrapa Comunicação para Transferência de Tecnologia, p.131198, 1999.

GOEDERT, W.J.; SOUSA, D.M.G.; LOBATO, E. Fósforo. In: GOEDERT, W.J. (Ed.). Solos dos cerrados: tecnologia e estratégias de manejo. São Paulo: Nobel, 1985. p.129-163.

GUIMARÃES, T.G.; MELO, V.F.; GOMES, P.C.; ALVARES, V.H. Eficiência de um fosfato parcialmente acidulado na produção de milho (Zea mays L.). In: CONGRESSO BRASILEIRO DE CIÊNCIA DO SOLO, 24., 1993, Goiânia. Resumos. Goiânia, Sociedade Brasileira de Ciência do Solo, 1993. p.215-216.

HORWITZ, W. Official Methods of Analysis of the Association of Official Analytical Chemists. Washington: Association of Official Analytical Chemists, 1970. 1015 p.

JAYACHANDRAN, K.; SCHWAB, A.P.; HETRICK, B.A.D. Micorrhizal mediation of phosphorus availability: synthetic iron chelates effects on phosphorus solubilization. Soil Science Society of American Journal, v.54, p.1447$55,1989$.

KAMINSKI, J.; PERUZZO, G. Eficácia de fosfatos naturais reativos em sistemas de cultivo. Boletim Técnico. Santa Maria: Núcleo Regional Sul da Sociedade Brasileira de Ciência do Solo. 1997, 31 p.

KATAYAMA, M. Nutrição e adubação de alface, chicória e almeirão. In: FERREIRA, M.E.; CASTELLANE, P.D.; CRUZ, M.C.P. Nutrição e adubação de hortaliças. Piracicaba: POTAFOS, 1993. 487 p. p. 141-8. Anais do simpósio sobre hortaliças, 1990.

LIN, C.; BUSSCHER, W.J.; DOUGLAS, L.A. Multifactor kinetics of phosphate reactions with minerals in acidic soils. I. Modeling and simulation. Soil Science Society of American Journal, v.47, p.1097-103, 1983.

MALAVOLTA, E. Elementos de nutrição mineral de plantas. São Paulo: Agronômica Ceres, 1980. $251 \mathrm{p}$

MALAVOLTA, E. ABC da adubação. 5. ed. São Paulo: Agronômica Ceres, 1989. 292 p.

NAKAGAWA, J.; PIERI, J.C. ; BULL, L.T. Efeito de cinco adubos fosfatados, com e sem calcário, no rabanete e da ação residual em rabanete e rúcula. Horticultura Brasileira, Brasília, v.7, n.1, maio 1989. Trabalho apresentado no $29^{\circ}$ Congresso Brasileiro de Olericultura, 1989.

NOVAIS, R.F.; SMYTH, T.J. Fósforo em solo e planta em condições tropicais. Viçosa: UFV, 1999. 399 p.

REIN, T.A., SOUSA, D.M.G.; LOBATO, E. Eficiência agronômica do fosfato natural Carolina do Norte em solo de cerrado. Reunião Brasileira de Fertilidade do Solo e Nutrição de Plantas, 21. 1994, Petrolina, PE. (Anais...), Petrolina, PE; SBCS/EMBRAPA-CPATSA.1994. p.38-40.

RIBEIRO, A.C.; GUIMARÃES, P.T.G.; ALVAREZ, V.H. Recomendação para uso de corretivos e fertilizantes em Minas Gerais ( $5^{a}$ aproximação). Viçosa: UFV, 1999. 359 p.

VAN RAIJ, B. Fertilidade do solo e adubação. Piracicaba: Agronômica Ceres/POTAFOS, 1991. 343 p. 